
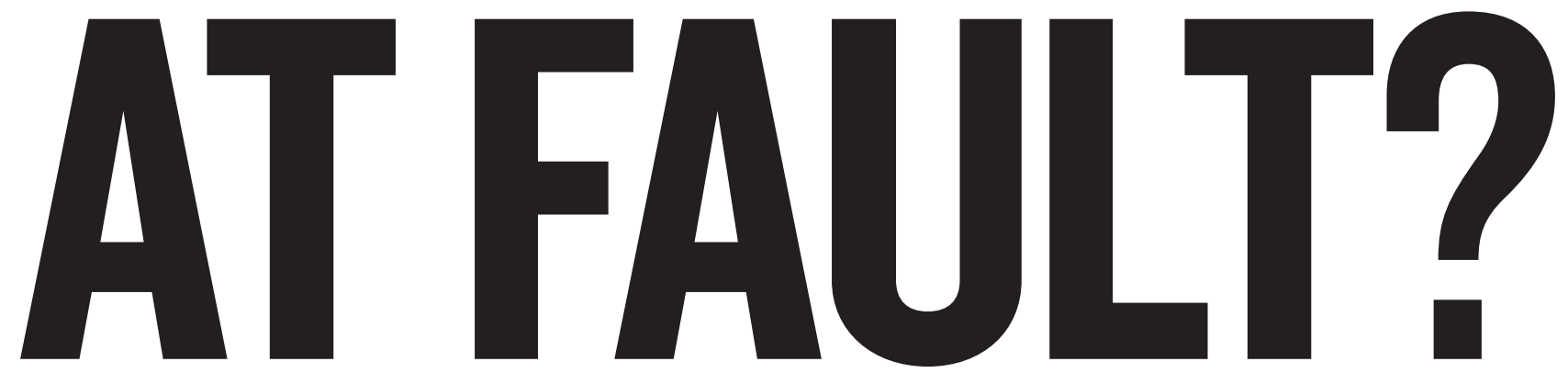

In 2009, an earthquake devastated the Italian city of L'Aquila and killed more than 300 people. Now, scientists are on trial for manslaughter. 


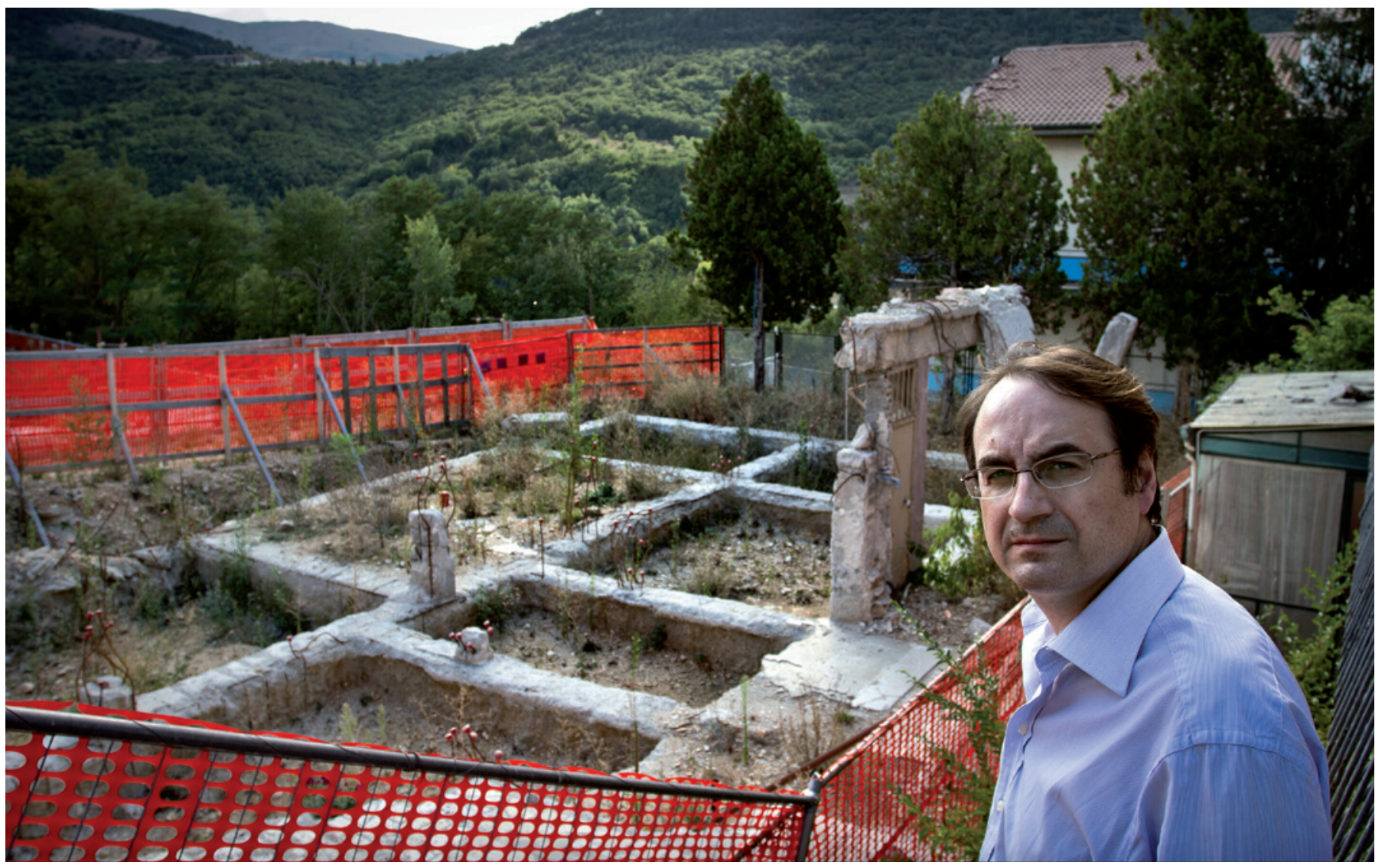

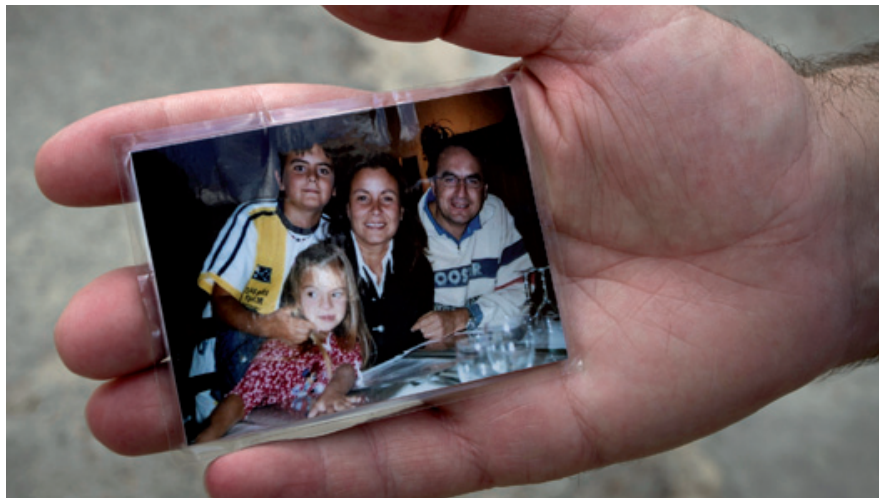

the ability to predict earthquakes, and everything to do with the failure of government-appointed scientists serving on an advisory panel to adequately evaluate, and then communicate, the potential risk to the local population. The charges, detailed in a 224-page document filed by Picuti, allege that members of the National Commission for Forecasting and Predicting Great Risks, who held a special meeting in L'Aquila the week before the earthquake, provided "incomplete, imprecise, and contradictory information" to a public that had been unnerved by months of persistent, low-level tremors. Picuti says that the commission was more interested in pacifying the local population than in giving clear advice about earthquake preparedness.

"I'm not crazy", Picuti says. "I know they can't predict earthquakes. The basis of the charges is not that they didn't predict the earthquake. As functionaries of the state, they had certain duties imposed by law: to evaluate and characterize the risks that were present in L'Aquila." Part of that risk assessment, he says, should have included the density of the urban population and the known fragility of many ancient buildings in the city centre. "They were obligated to evaluate the degree of risk given all these factors," he says, "and they did not."

"This isn't a trial against science," insists Vittorini, who is a civil party
Vincenzo Vittorini's apartment building collapsed in the 2009 quake, killing his wife and daughter. He says that he feels "betrayed by science".

to the suit. But he says that a persistent message from authorities of " $\mathrm{B}$ calm, don't worry", and a lack of specific advice, deprived him and others of an opportunity to make an informed decision about what to do on the night of the earthquake. "That's why I feel betrayed by science," he says. "Either they didn't know certain things, which is a problem, or they didn't know how to communicate what they did know, which is also a problem."

Although the outcome of the trial may not be known for months, if not years, the events leading up to the earthquake are already being viewed as a sobering case study in risk assessment and public communication - a scenario that might easily be replayed in a future that includes not just 'conventional' natural disasters (such as volcanic eruptions, earthquakes, and tsunamis), but also extreme weather events (such as tornadoes, hurricanes, floods and droughts) perhaps cooked up by climate change. The trial has already had a chilling effect on scientists' willingness to share their expertise with the public. "When people, when journalists, asked my opinion about things, I used to tell them, but no more. Scientists have to shut up," says Boschi, whose successor at the INGV was appointed last month. Others see the case as an indictment of the obfuscating, probabilistic language with which scientists characterize the uncertain potential of natural disasters. Selvaggi, one of the indicted scientists, says that the charges serve as a "dangerous" warning to researchers, who may find themselves in legal trouble because of the way that non-scientists such as public officials or journalists translate their risk analyses for public consumption. Given the novelty of the issues, says defence lawyer Filippo Dinacci, "not only the press, but the academic legal community will be watching this case with great interest".

Thomas Jordan, director of the Southern California Earthquake Center at the University of Southern California in Los Angeles, and chair of the International Commission on Earthquake Forecasting (ICEF), which reviewed the L'Aquila events in a report released in May, 
says that in his view the prosecution charges have "no merit". But he adds that the trial is nonetheless a "watershed case" that will force seismologists worldwide to rethink the way they describe low probability, high-risk events, as well as an opportunity for the scientific community at large to assess "rising public expectations" about how information on natural disasters should be handled. "The public expects authoritative, transparently available information," he says, "and we need to say what we know in an explicit way."

In Jordan's view, "It has to be done right, and it was not in L'Aquila."

\section{SEISMIC REPUTATION}

L'Aquila is - or was - a jewel of medieval beauty set in the middle of one of the most seismically dangerous zones in Italy. Surrounded by the massive peaks of the restless Apennine mountain range, the city, capital of the Abruzzo region, was largely destroyed by earthquakes in 1461 and in 1703. Its seismic reputation was such that the nineteenth-century British travel writer Augustus Hare noted that, "nature suddenly often sets all the bells ringing and the clocks striking, and makes fresh chasms in the old yellow walls".

Its most recent seismic tragedy began in October 2008, when dozens of low-magnitude tremors began to hit the city and surrounding areas along the Aterno River valley (see 'A shaken city'). Known as seismic swarms, these tremors continued intermittently over the first three months of 2009; according to

Picuti, they numbered 69 in January, 78 in February and 100 in March, with an additional 57 shocks during the first five days of April. "It was like this almost every day," says Pier Paolo Visione, a local accountant, shaking a table in a restaurant with a slow but vigorous motion that nearly topples a bottle of the local red Montepulciano wine. "I had never been afraid of earthquakes before, but my skin began to crawl." (Visione's sister died in the quake, and he is a civil party to the suit.)

Unnerving though these clusters may be, experts agree that seismic swarms rarely precede major earthquakes. In 1988, seismic engineer Giuseppe Grandori, now professor emeritus at the Polytechnic of Milan, and his colleagues published a retrospective analysis of seismic swarms in three other earthquake-prone Italian localities (G. Grandori et al. Bull. Seismol. Soc. Am. 78, 1538-1549; 1988). They concluded that a medium-sized shock in a swarm forecasts a major event within several days about $2 \%$ of the time, and Grandori says that the same was probably true for the region around L'Aquila.

Translating these risks is extremely challenging for civil defence officials. In Grandori's view, there is a $98 \%$ probability of a false alarm if officials issue an alert, yet a terrible price to pay in loss of life and property if they fail to issue a warning and a major quake occurs. After a medium-sized shock in a seismic swarm, the risk of a major quake can increase anywhere from 100-fold to nearly 1,000-fold in the short term, according to Jordan, although the overall probability remains extremely low. "What do you tell people in that situation?" he says. "You're sort of between Scylla and Charybdis on this thing."

To this difficult exercise in risk probability was added a wild card in the case of L'Aquila: a resident named Giampaolo Giuliani began to make unofficial earthquake predictions on the basis of measurements of radon gas levels. Giuliani, who had worked for 40 years as a laboratory technician, including 20 years at the nearby Gran Sasso National Laboratory until his retirement in 2010, had deployed four home-made radon detectors throughout the region.

The idea behind radon measurement, Giuliani says, is that emissions of the gas fluctuate significantly in the 24 hours before an earthquake. But their use as a reliable short-term predictor of earthquakes has never been scientifically proved or accepted. The recent ICEF report deemed Giuliani's findings "unsatisfactory", and he has yet to publish a single peer-reviewed paper on his radon work. Nonetheless, he maintained an open website that posted real-time radon measurements from his detectors, and in interviews with journalists and in an informal mobilephone network, Giuliani made predictions about low-level seismic activity. Although the ICEF report notes that he made two false forecasts, The Guardian newspaper dubbed him "The Man Who Predicted An Earthquake”, after the April 2009 quake hit.

As word spread about Giuliani's unofficial predictions, even more unease percolated through the population. Marcello Melandri, the lawyer for Boschi, says that Giuliani had been terrifying local residents, and that Guido Bertolaso, head of Italy's Department of Civil Protection agency, "was very worried about the population of L'Aquila". On $30 \mathrm{March}$, Giuliani says, national civil-protection officials cited him for procurato allarme - essentially instigating public alarm or panic - and forbade him from making any public pronouncements.

That same day, L'Aquila was hit by an intense, magnitude 4.1 shock in the afternoon that deeply rattled local residents. Vittorini, who performs his surgeries in the nearby town of Popoli, received an anguished call from his wife and son. (His daughter was not at home at the time.) He urged them to leave the house immediately and get outside, he says. L'Aquila's mayor, Massimo Cialente, ordered the evacuation of several public buildings and closed the De Amicis primary school to inspect for structural damage.

Italian seismologists had been monitoring the swarm in the Abruzzo region for months, and notifying civilprotection officials in real time of every tremor with a magnitude of greater than 2.5. Now, given the growing unease in L'Aquila, Bertolaso decided to convene an unusual meeting of the risks commission. The commission normally meets in Rome to assess the probability of earthquakes, volcanoes and other natural disasters, but this meeting was to take place the next day in L'Aquila. The goal, according to a press release from the Department of Civil Protection, was to furnish citizens in the Abruzzo region "with all the information available to the scientific community about the seismic activity of recent weeks".

\section{MEETING OF MINDS}

The now-famous commission meeting convened on the evening of 31 March in a local government office in L'Aquila. Boschi, who had travelled by car to the city with two other scientists, later called the circumstances "completely out of the ordinary". Commission sessions are usually closed, so Boschi was surprised to see nearly a dozen local government officials and other non-scientists attending the brief, one-hour meeting, in which the six scientists assessed the swarms of tremors that had rattled the local population. When asked during the meeting if the current seismic swarm could be a precursor to a major quake like the one that levelled L'Aquila in 1703, Boschi said, according to the meeting minutes: "It is unlikely that an earthquake like the one in 1703 could occur in the short term, but the possibility cannot be totally excluded." The scientific message conveyed at the meeting was anything but reassuring, according to Selvaggi. "If you live in LAquila, even if there's no swarm," he says, “you can never say, 'No problem.' You can never say that in a high-risk region." But there was minimal discussion of the vulnerability of local buildings, say prosecutors, or of what specific advice should be given to residents about what to do in the event of a major quake. Boschi himself, in a 2009 letter to civil-protection officials published in the Italian weekly news magazine L'Espresso, said: "actions to be undertaken were not even minimally discussed".

Many people in L'Aquila now view the meeting as essentially a public-relations event held to discredit the idea of reliable earthquake prediction (and, by implication, Giuliani) and thereby reassure local residents. Christian Del Pinto, a seismologist with the civil-protection 


\section{A SHAKEN CITY}

L'Aquila lies in one of the most seismically hazardous zones in Italy (see map). In early 2009, a series of tremors hit the region.

The graph shows the daily number of earthquakes, with the bar colour indicating magnitude. The tremors (shown in detail in the

inset graph) were followed on 6 April by a devastating magnitude- 6.3 earthquake, which killed more than 300 people.
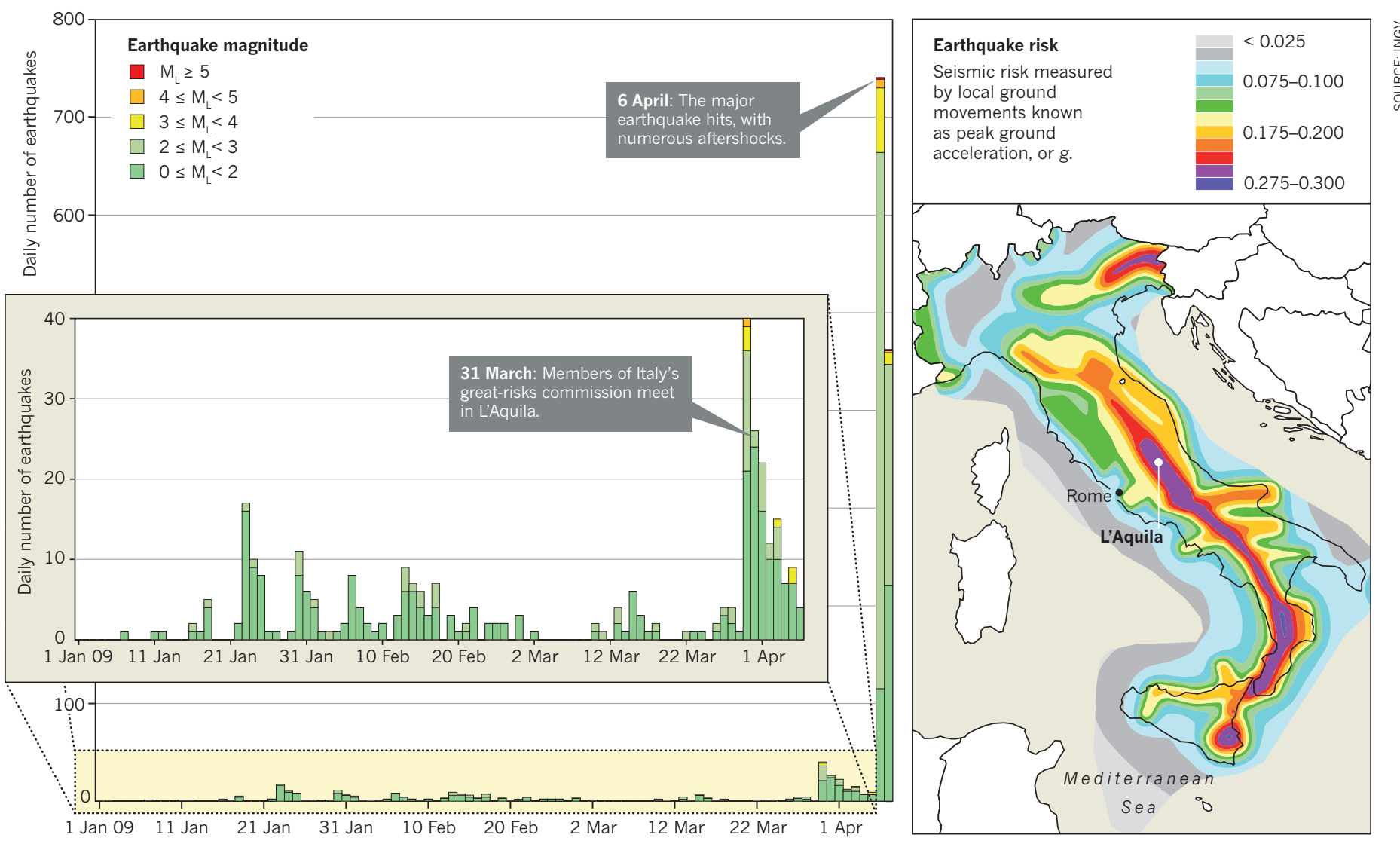

Bernardinis made these remarks before the actual meeting.)

department for the neighbouring region of Molise, sat in on part of the meeting and later told prosecutors in L'Aquila that the commission proceedings struck him as a "grotesque pantomine". Even Boschi now says that "the point of the meeting was to calm the population. We [scientists] didn't understand that until later on."

What happened outside the meeting room may haunt the scientists, and perhaps the world of risk assessment, for many years. Two members of the commission, Barberi and De Bernardinis, along with mayor Cialente and an official from Abruzzo's civil-protection department, held a press conference to discuss the findings of the meeting. In press interviews before and after the meeting that were broadcast on Italian television, immortalized on YouTube and form detailed parts of the prosecution case, De Bernardinis said that the seismic situation in L'Aquila was "certainly normal" and posed "no danger", adding that "the scientific community continues to assure me that, to the contrary, it's a favourable situation because of the continuous discharge of energy". When prompted by a journalist who said, "So we should have a nice glass of wine," De Bernardinis replied "Absolutely", and urged locals to have a glass of Montepulciano.

The suggestion that repeated tremors were favourable because they 'unload', or discharge, seismic stress and reduce the probability of a major quake seems to be scientifically incorrect. Two of the committee members - Selvaggi and Eva - later told prosecutors that they "strongly dissented" from such an assertion, and Jordan later characterized it as "not a correct view of things". (De Bernardinis declined a request for an interview through his lawyer, Dinacci, who insisted that De Bernardinis's public comments reflected only what the commission scientists had told him. There is no mention of the discharge idea in the official minutes, Picuti says, and several of the indicted scientists point out that De

That message, whatever its source, seems to have resonated deeply with the local population. "You could almost hear a sigh of relief go through the town," says Simona Giannangeli, a lawyer who represents some of the families of the eight University of L'Aquila students who died when a dormitory collapsed. "It was repeated almost like a mantra: the more tremors, the less danger." "That phrase," in the opinion of one L'Aquila resident, "was deadly for a lot of people here."

The press conference and interviews, prosecutors argue, carried special weight because they were the only public comments to emerge immediately after the meeting. The commission did not issue its usual formal statement, and the minutes of the meeting were not even prepared, says Boschi, until after the earthquake had occurred. Moreover, it did not issue any specific recommendations for community preparedness, according to Picuti, thereby failing in its legal obligation "to avoid death, injury and damage, or at least to minimize them".

Picuti argues that the fragility of local housing should have been a central component in the commission's risk assessment. "This isn't Tokyo, where the buildings are anti-seismic," he says. "This is a medieval city, and that raises the risk." In 1999, Barberi himself had compiled a massive census of every seismically vulnerable public building in southern Italy; the survey, according to the prosecution brief, indicated that more than 550 masonry buildings in L'Aquila were at mediumhigh risk of collapsing in the event of a major earthquake.

The failure to remind residents of earthquake preparedness procedures in the face of such risks is one of the reasons that John Mutter, a seismologist at Columbia University's Lamont-Doherty Earth Observatory, declined to sign the open letter circulated to support the Italian scientists. Mutter says that in his opinion, "these guys shouldn't go to 
jail, but they should be fined or censured because they should have said something other than what they said. To say 'don't worry' - that sort of thing just isn't helpful. You need to remind people of their earthquake drills: if they feel the house moving, get out of the building if you can, or get under a table or a door frame if you can't. Do all the things that we know save lives."

As part of the prosecution's case, Picuti argues in his brief that local residents made fateful decisions on the night of the earthquake on the basis of statements made by public officials outside the meeting. Maurizio Cora, a lawyer who lived not far from Vittorini, told prosecutors that after the 30 March shock, he and his family retreated to the grounds of L'Aquila's sixteenth-century castle; after the 11 p.m. foreshock on 5 April, he said his family "rationally" discussed the situation and, recalling the reassurances of government officials that the tremors would not exceed those already experienced, decided to remain at home, "changing our usual habit of leaving the house when we felt a shock". Cora's wife and two daughters died when their house collapsed.

"That night, all the old people in L'Aquila, after the first shock, went outside and stayed outside for the rest of the night," Vittorini says. "Those of us who are used to using the Internet, television, science - we stayed inside."

\section{DISPUTED ADVICE}

In an interview in the Rome offices of his lawyer, Boschi derided as "absurd" the idea that he in any way played down the risk to L'Aquila. Brandishing a copy of the INGV's seismic hazard map of Italy, which shows a broad swath of the Apennines in bright hues indicating high risk, the tall, silver-haired geophysicist insisted: "No one can find a single piece of paper where I say, 'Be calm, don't worry'. I have said for years that the Abruzzo is the most seismologically dangerous zone in all of Italy. It's as if I suddenly became an imbecile. I'm accused of being negligent!" $\mathrm{He}$ was not invited to participate in the press conference after the meeting, he says, and didn't even know about it until after his return to Rome.

Attorneys for the other scientists all insist that the charges are without foundation, while raising additional arguments. Barberi's lawyer, Petrelli, acknowledges that the meeting was intended "in part" to defuse the panic over Giuliani's predictions, but insists that everything his client said was scientifically sound and correct. To convey the difficulty of communicating risk assessments, he offers the analogy of being asked the safest way to travel, and recommending flying because it is statistically much safer than car or train. "If the person takes the plane, and the plane is involved in an accident, this doesn't mean that my advice was wrong," he said. "I gave the right advice, since scientific advice is based on statistics, and the statistics don't exclude the possibility of an event that we would like to avoid."

Alessandra Stefano, the lawyer for Calvi, says that the mass media has played a part in the case by disseminating incorrect information about "especially delicate" scientific matters. Eva's lawyer, Alfredo Biondi, has pointed out that in 1985, the then-head of civil protection, Giuseppe Zamberletti, was investigated for instigating a public panic when he ordered the evacuation of several villages in northwest Tuscany after a seismic swarm; on that occasion, no major quake occurred. Antonio Pallotta has argued that his client, Selvaggi, was not an official member of the commission.

As for the statement that seems to have resonated most with the residents of L'Aquila - De Bernardinis's claim that during seismic swarms, repeated tremors were "favourable" Dinacci says of his client: "He's not a seismologist, he's a hydraulic engineer," and that he had only relayed what the scientists had told him. As to De Bernardinis's suggestion to have a glass of Montepulciano, Dinacci says, “This was a joke! $\rightarrow$ NATURE.COM To hear Stephen S. Hall discussing the events in L'Aquila: go.nature.com/otcael

To have made a joke about a glass of wine and then face a conviction is absurd. It's something out of the Middle Ages."

The outcome of the trial that begins next week in L'Aquila can no more be predicted than can earthquakes themselves. It will ultimately be up to a single magistrate to decide whether the actions of the commission, and the alleged "erroneous information" released by officials outside the meeting, rise to the level of criminal culpability. Although defence lawyers say that the prosecution's case is logically flawed, the stakes are high. If convicted, the scientists could face up to 15 years in jail, according to prosecutors. In addition, plaintiffs in a separate civil case are seeking damages in the order of $€ 22.5$ million (US\$31.6 million).

\section{AFTER SHOCK}

Irrespective of the verdict, the episode has been a painful tutorial about the importance of clear public communication when potential disasters loom. The commission and the civil-protection department "got trapped in the wrong conversation because of the hullaballoo that was happening" around the unofficial predictions of earthquakes, says Jordan. "The issue became, is there going to be an earthquake or not, and that choice is the wrong way to talk about this." Mutter adds that in his opinion, the commission's focus on whether earthquakes could be predicted or not ultimately didn't tell people what they wanted to know. "People aren't stupid," he says. "They know we can't predict earthquakes. They just want clear advice on what they should do."

The recent ICEF report argues that frequently updated hazard probabilities are the best way to communicate risk information to the public. "Seismic weather reports, if you will, should be put out on a daily basis," Jordan says. "Nobody has set up a good system for doing this, and our understanding of the 'weather' in this case is very poor, so we can only see through the glass darkly." But in an age of social media and instantaneous communication, he says, misinformation travels fast, and the public needs clear, real-time risk assessment. As Selvaggi warns, the number of situations in which scientists are asked to assess hazard is certain to rise. "We have an increasing number of extreme events," he said, "and we have increasing numbers of people living in high-risk regions. It's time to address this problem."

Jordan says that the L'Aquila incident raises one other fundamentally important issue about risk assessment. "The role of science is to present information about hazards," he says. "But it's the role of the decision-makers to take that information, and a lot of other information, in order to make decisions about public welfare." In fact the legal fight in L'Aquila is viewed by some as a philosophical dispute between scientists, who believe that their role is pure hazard assessment, and the local prosecutors, who argue that Italian law obliges scientific advisers to evaluate the fragility of buildings and other factors in their assessment of risk.

Scientists will also have to work hard to convince the public, at least in L'Aquila, that frequent, probabilistic risk assessment is a better way to protect them than age-old traditions. As Vittorini told Picuti after the earthquake, the messages from the commission meeting "may have in some way deprived us of the fear of earthquakes. The science, on this occasion, was dramatically superficial, and it betrayed the culture of prudence and good sense that our parents taught us on the basis of experience and of the wisdom of the previous generations."

Glancing at an image of his deceased wife and daughter on his mobile phone, Vittorini says: "We're not crazy people. We just want accountability. We hope this trial can be a symbol of change." - SEE WORLD VIEW P. 251

Stephen S. Hall is a science writer based in New York who also teaches public communication to graduate students in science at New York University. 